\title{
Structure of Remote Work in Public Education: A Rapid Scoping Review
}

\author{
David C. Coker \\ Fort Hays State University Virtual College, United States \\ E-mail: cokerd@danville118.org
}

Received: March 29, $2021 \quad$ Accepted: July 20, $2021 \quad$ Published: August 11, 2021

doi: 10.5296/ire.v9i2.18474 URL: https://doi.org/10.5296/ire.v9i2.18474

\begin{abstract}
Remote learning predominates the research literature during the COVID-19 pandemic, while remote work structures and workflow research were unknown. A rapid scoping review was conducted for remote work and workflow for 2020-2021. After locating and screening articles, a qualitative synthesis of the literature explored trends and themes using thematic analysis. A discussion of the perplexities of remote work and workflow, issues which impact every student and teacher, examined the problems of the new normal. Recommendations were to use Fayol's principles as a guide within the context of using a holistic schooling experience focus, a formalized policy, and making leadership and management standardized and present within a remote environment. Limitations were discussed, and future directions for research gave a plan to improve remote work and learning.
\end{abstract}

Keywords: Workflow, Remote work, COVID-19, Scoping review, Educational policy, Remote learning

\section{Introduction}

COVID-19 forced public education to rapidly adapt to remote and online learning. A great deal of research - indeed the overwhelming majority - dealt with remote learning (Bond, 2020; Carrillo \& Flores, 2020). As Bond (2020) and others convincingly showed, remote learning was problematic, and what students learned was often questionable. Further research suggested students neither attended nor participated in numbers similar to pre-COVID-19, meaning learning loss was common for most except the top students (Coker, 2020a; Kuhfeld et al., 2020). In the rush to remediate and improve remote learning, another important factor was overlooked: work flow and remote work.

A scoping review produces a knowledge synthesis and translates research into actionable results (Kastner et al., 2012). A literature review of the problems of remote work and workflow 
detailed the importance of creating effective supervision and leadership. Remote work and workflow structures were analyzed using a scoping review analysis, with review of the exigent literature, screening of results, and a thematic analysis using Fayol's five principles. A discussion and recommendations were given on how educational leadership and administration can improve remote work practices for employees to develop a sustainable, coherent workflow.

\section{Literature Review}

Educators were sent home, but how to connect students online and create effective teaching were the primary concern beyond generalized recommendations (e.g., Larson et al., 2020). Remote work, or the leadership, direction, management, and supervision of remote employees in the public school sector, was not well defined. Workflow is the creation of a structure and routine for remote employees. Constructing effective remote work and workflow, where there was a balance with all stakeholders and the utilization of technology to develop effective work routines, were two key factors to managing a remote workforce (Tanpipat et al., 2021). Research outside education was much more robust, but recreating the schooling work environment at home remained an unknown.

Henri Fayol was a pioneer in strategic leadership. Fayol stated there were five major areas to consider in leading an organization: planning (having foresight and anticipation of the future), organizing, command, coordination, and control (Wren et al., 2002). The purpose was to develop a unity of direction, where all resources pointed together in harmony. Ravanelli et al. (2020) examined teacher readiness for remote work by assessing four dimensions: appropriateness, management, change-specific efficacy, and personal valence, finding most teachers felt ready for remote work. Pedagogic competence was a necessary element. How teachers dealt with Fayol's five principles in the literature was generally absent beyond how teachers felt and coped with the change to remote learning.

Workflow was fragmented and ill-defined in the new COVID schooling experience. Teaching was the focus of educational supervision (Rusdiana et al., 2020); lacking was how to start and end the workday, collaborate and communicate with colleagues, and remain socially and emotionally connected. Trying to figure out how to teach sapped up all the energy, yet other fields found solving the technical, cognitive, and ergonomic problems of remote work were critical to creating engaged, happy employees (Bartnicka et al., 2020). Work conditions defined employee engagement and significantly impacted stress (Kusumaningtiar \& Anggraini, 2020), but administrative support might not be enough to mediate the strain of working from home (Mardianah \& Hidayat, 2020). The popular and academic literature, as well as professional development and books, focused on remote learning almost exclusively.

Leadership and the work environment impact teachers' performance (Aropah \& Sumertajaya, 2020), with the move to remote work possibly exacerbating iniquities (Lord, 2020). A cursory glance of collective bargaining agreements of public schools revealed little was mentioned about creating an effective, efficient educational leadership and administration structure in the remote environment. Sliż (2020) found most organizations lacked formal written plans for school administrators and employees to recreate the structure of face-to-face (F2F) schools in a remote environment. Marginalized populations were probably hurt the worst, lacking the technology and supports to participate in the new school (Coker, 2021). 
An organization's definition of organizational citizenship behavior emits negative and positive connections with each employee's performance and wellbeing (Smith et al., 2020). Employees described working more, but most felt the tradeoff improved motivation, imparted greater control over one's work, and removed conflicts in the workplace (Mesquita et al., 2020). There were many reports of the benefits and downsides to remote work and workflow, but direct research into the hows and whys - the practical implementation-were not as richly researched.

\section{Methodology}

A scoping review is a rapid examination of the exigent literature to map research, synthesize results, and describe the gap in the literature (Tricco et al., 2018). Unlike a systematic review, a scoping review considers all artifacts for review, including nontraditional sources and the gray literature (O'Flaherty \& Phillips, 2015). The guidelines outlined by Tricco et al. (2018) were followed for a methodology using Preferred Reporting Items for Systematic Reviews and Meta-Analyses-Scoping Reviews (PRISMA-ScR), with some exceptions listed.

The research question was broad: What were the structures of remote work and workflow conditions which could improve public school leadership and administration? Because the field, previously reviewed for other articles by this author found little research into the nature of remote work, the problem was broadly examined for all remote work and workflow. From March 9-11, 2021, a search was conducted on Microsoft Academics using three search terms: "remote work," "virtual work," and "work from home." A secondary search using the terms was conducted with Google Scholar. Inclusion and exclusion criteria were listed in Table 1.

Table 1. Inclusion and exclusion criteria

\begin{tabular}{lll}
\hline Criteria & Inclusion & Exclusion \\
\hline $\begin{array}{l}\text { Time } \\
\text { period }\end{array}$ & 2020-2021 & Studies outside the date range. \\
Language & English & Studies in a different language. \\
& & \\
$\begin{array}{l}\text { Type } \\
\text { article }\end{array}$ & $\begin{array}{l}\text { All articles, including policy papers } \\
\text { and research studies. }\end{array}$ & $\begin{array}{l}\text { Articles which described teachers' } \\
\text { reactions. }\end{array}$ \\
Study focus & $\begin{array}{l}\text { Articles which had a contribution to } \\
\text { workflow and/or remote work. }\end{array}$ & $\begin{array}{l}\text { Articles which did not deal with } \\
\text { workflow and dealt primarily with } \\
\text { barriers. }\end{array}$ \\
\hline
\end{tabular}

All articles were screened by the author; because there was not a second reviewer, as proposed by Tricco et al. (2018), a secondary examination of all articles by hand and with a computer program was conducted to reexamine possible overlooked articles. The result was many more articles were screened than normal, and ones previously selected underwent reconciliation, or comparison with the criteria for inclusion. Any article possibly meeting 


\section{Macrothink}

inclusion criteria were downloaded and reviewed in the article's entirety.

\subsection{Data Collection}

All articles were examined following the guidance of PRISMA-ScR, without regard for peer review or other formal avenues of research, to develop further hypotheses and research questions (Tricco et al., 2016). From March 9-11, 2021, all articles were searched and screened. Results were saved in Microsoft Excel, along with reasons for inclusion or exclusion. After receiving a Microsoft API, VosViewer (VosViewer 1.6.16, van Eck \& Waltman, 2010) and Publish or Perish (Harzing, 2007) were used to collect the results, check for duplicates and if articles were in English, as shown in Figure 1.

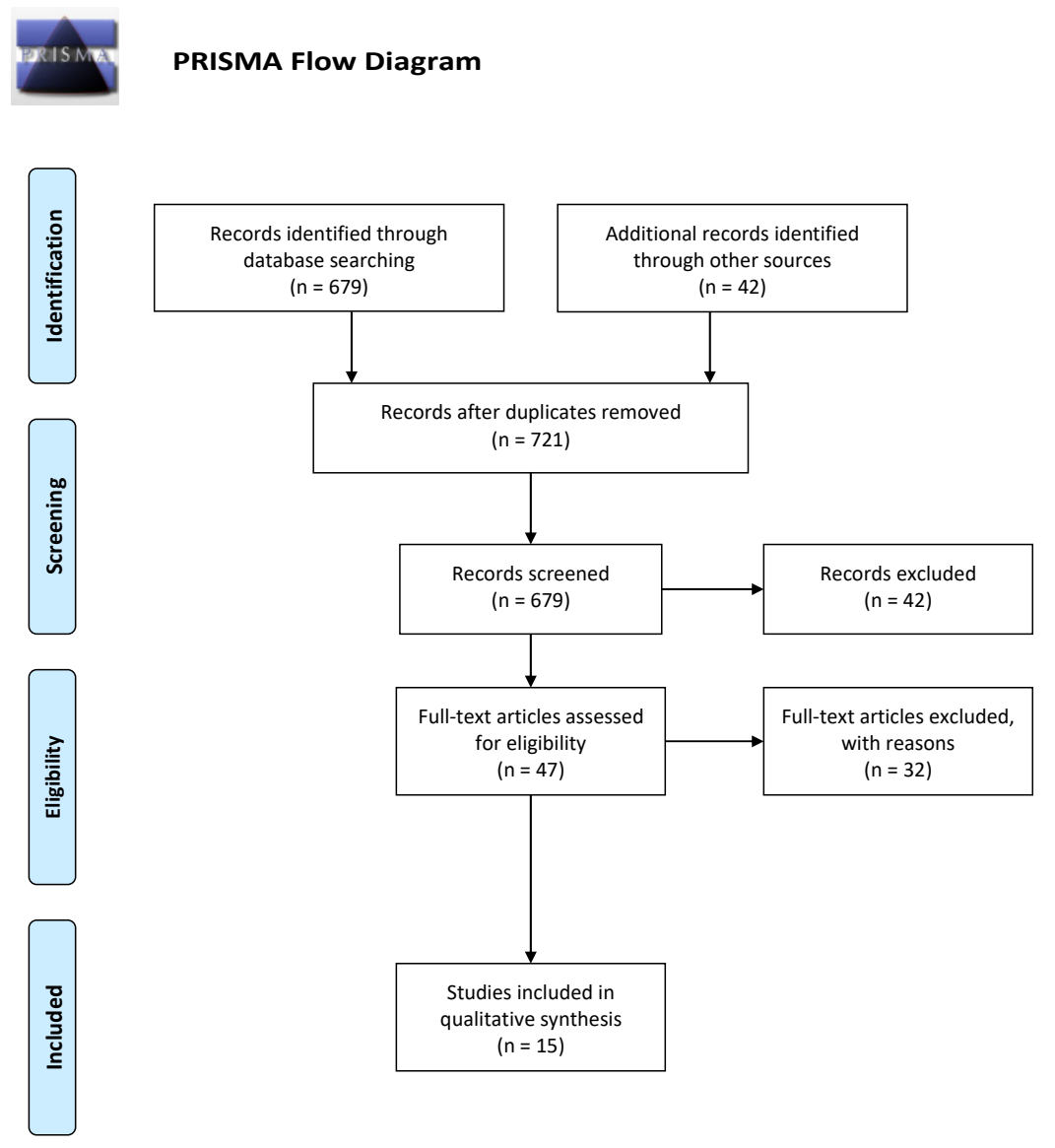

Figure 1. Selection of studies: PRISMA (Preferred Reporting Items for Systematic Reviews and Meta-Analyses) flowchart. Reprinted from Moher, D., Liberati, A., Tetzlaff, J., Altman, D. G, \& The PRISMA Group. (2009). Preferred Reporting Items for Systematic Reviews and Meta-Analyses: The PRISMA Statement. PLoS Med 6(7): e1000097

Initial exclusion during screening $(N=42)$ was either the articles were unavailable or were not in English. If an abstract was included, the article would have been included. The second round of exclusions during eligibility $(N=32)$ was expected: All articles dealt with barriers and positive ramifications of remote work, but the articles did not directly deal with how to structure remote work and workflow. For example, many articles described the stressful 
conditions of remote work. After review, 15 articles were included in the scoping review.

\subsection{Sample}

The inclusion criteria generated 15 articles. As shown in Table 2, most articles were policy papers, with few research articles. Many articles seemed to be more general recommendations than specifically about problems of workflow. If an article had a strong connection with workflow, it was included in the study. Articles were from around the world.

Table 2. Description of included studies

\begin{tabular}{lllr}
\hline Articles & Type & Results & \\
\hline Graves, L. M., \& Karabayeva, A. (2020). & Policy paper & Policy on improved \\
Managing virtual workers-strategies for & & supervision & of \\
success. IEEE Engineering Management & & employees. & \\
Review, 48(2), 166-172. & &
\end{tabular}

Hope, J. (2020). Working from home? Follow these tips for successful remote work. The Successful Registrar, 20(3), 9-9.

Howard-Grenville, J. (2020). How to Policy paper sustain your organization's culture when everyone is remote. MIT Sloan Management Review, 61(4), 1-4.

Ilag, B. N. (2021). Tools and technology for effective remote work. International Journal of Computer Applications, 174(21), 13-16.

Jensen, N., Lyons, E., Chebelyon, E., Le Bras, R., \& Gomes, C. (2020). Conspicuous monitoring and remote work. Journal of Economic Behavior \& Organization, 176, 489-511.

Karanikas, N., \& Cauchi, J. (2020). Literature review on parameters related to work-from-home (WFH) arrangements. Queensland University of Technology.

Knight, M., \& Taylor, R. (2020). Flexible work strategies for public accounting: Well-designed procedures can help CPA firms make effective use of remote work
Brief policy paper

Provides three suggestions.

Recommendations to build an organization's culture remotely.

Explores productivity issues and procedures
Field work in Conspicuous monitoring implementing employee monitoring. was found to improve employee productivity.
Policy paper and Literature review of best literature review. practices.
Research paper into Examined work procedures using a strategies survey $(N=113)$ of worldwide. international firms. 
and employee-friendly scheduling. Journal of Accountancy, 229(2), 22.

Leonardi, P. M. (2020). COVID-19 and the Policy paper new technologies of organizing: digital exhaust, digital footprints, and artificial intelligence in the wake of remote work. Journal of Management Studies.

Limoncelli, T. A. (2020). Five nonobvious remote work techniques: Emulating the efficiency of in-person conversations. Queue, 18(3), 29-38.

Lopez-Leon, S., Forero, D. A., \& Ruiz-Díaz, P. (2020). Recommendations for working from home during the pandemic (and Beyond). Work, (Preprint), 1-5.

Manokha, I. (2020). Covid-19: Teleworking, surveillance and 24/7 work. Some reflexions on the expected growth of remote work after the pandemic. Political Anthropological Research on International Social Sciences (PARISS), 1(2), 273-287.

Popovici, V., \& Popovici, A. L. (2020). Remote work revolution: Current opportunities and challenges for organizations. Ovidius University Annals, Economic Sciences Series, 20(1), 468-472.

Sull, D., Sull, C., \& Bersin, J. (2020). Five ways leaders can support remote work. MIT Sloan Management Review, 61(4), 1-10.

Tsareva, N. A., \& Yu, S. (2020). Remote work: Development of employee digital competence. Revista de la Universidad del Zulia, 11(31), 131-140.
Research in human resources using a survey $(N=441)$ worldwide.

Research into Provides a theoretical remote work using surveys $(N=177)$ in Russia.

General suggestions.

and

historical background as well as specific practices.
Details how technology can track all facets of employment.

Provides five suggestions.

Provides general suggestions.

Provides specific recommendations on monitoring employees.

Examines problems and solutions 
Whillans, A., Perlow, L., \& Turek, A. Research into Provides problems and (2021). Experimenting during the shift to teamwork using solutions into managing virtual team work: Learnings from how interviews $(N=51)$ teams and fostering teams adapted their activities during the in the United States. collegiality.

COVID-19 pandemic Information and

Organization, 100343.

\subsection{Data Analysis}

After inclusion, articles $(N=15)$ were systematically reviewed by first reading the articles, a secondary reading with notes, and a tertiary examination with systematic coding. VosViewer (VosViewer 1.6.16, van Eck \& Waltman, 2010) and Publish or Perish (Harzing, 2007) showed relationships between researchers and search terms. Microsoft Excel was used to perform thematic analysis.

Thematic analysis was performed using deductive qualitative analysis. First, Fayol's five principles of strategic leadership were defined and operationalized. Next, in vivo and descriptive codes were generated, as well as memos and a constant comparison of findings. Third, axial codes were developed using Fayol's principles using horizontalism; since this study was a scoping review, all different codes were emphasized over counting the prevalence. Finally, the data were reexamined for subordinate categories within superordinate categories, and the themes were written as a narrative production. To ensure trustworthiness and credibility, the plan for data analysis was followed and a reconciliation was conducted, where results were compared with the original artifacts.

Bartosiak (2020) and Wren et al. (2002) formed the basis for operationalizing Fayol's principles. Operationalized definitions were the following:

- Plan: A relevant, flexible working plan of action.

- Control: Everything happens according to the plan and it is kept up to date.

- Coordination: Timing and sequencing.

- Command: Bring together senior staff and ensure unity of activity.

- Organization: Flow and use of resources, communication, and duties known.

A codebook was developed. After the review, a narrative was produced to display the results.

\subsection{Results}

VosViewer revealed six major terms in remote work studies: COVID, pandemic, paper, work, organization, and worker. Few strong links existed between the authors included in the study, as the field of developing workflow in remote work was so nascent. Only five articles were research articles, and of the five, only one was direct field work versus survey analysis. Fayol's five categories primarily dealt with planning, with all four categories combined not equaling planning. One can surmise the major gap in the literature: Little research moved beyond the planning phase to implementation.

Planning had three major subordinate categories: formality, boundary maintenance, and obstacle identification. A formal plan standardizes practices and maps out an organization's readiness, establishes routines, implements metrics of success, and selects digital platforms. 
Boundary maintenance, also a major theme of barriers in the COVID literature, should result in reproducing an organization's culture, developing a home office, and the ability to disconnect. An important component of boundary maintenance would include childcare and the ability to disconnect from work after hours, as the spaces of work and home were colocated.

Within the planning realm, obstacles predominated the concerns of establishing a workflow. Social connections and autonomy were the two general issues. There was worry isolation would harm employees, as traditional socialization and communication broke down in remote work. Autonomy was both a positive and a negative. There was a work intensification, which might also harm boundary maintenance. Besides concerns of lack of productivity due to procrastination and self-doubt, there was the autonomy paradox, were employees find freedom to choose what or how becomes a nightmare of never-ending work.

Control involved the direct supervision and management of employees. Some spoke about managerial training and supervision, but two articles operationalized the ideas: conspicuous control and examining the digital exhaust. Conspicuous control utilized technology to monitor every keystroke and action of an employee during the workday. The digital exhaust meant everything a person does with technology produces a record which can be monitored, quantified, and used for future planning. All ideas were connected to cultural redirection, or reorienting the employees during the transition to remote work.

Coordination looked at keeping everything moving in unison and toward the common goal. Some ideas were extremely common, such as check in, technical support, and frequent, short meetings. Other ideas sought to recognize the shift to remote work could translate into drastically different expectations for teachers. Reduced workweek, flex jobs, more paid time off, and job sharing would be much easier in a remote environment than F2F. Employees in all aspects would also need to report availability. Another recommendation was either everyone was remote or no one was, as it would be difficult to coordinate, at the same time, mixed teams of remote and $\mathrm{F} 2 \mathrm{~F}$.

Command would have to be reenvisioned, both at the microlevel and the macrolevel. Teamwork formation and maintenance take on very different components in a remote environment. There would need to be administrative support, and mentoring would have to be built in formally and informally. Employees, once they know the requirements, might game the system; command would have to look at the alignment of metrics with results. Developing the culture for a successful experience would sometimes require a cultural censure, as new experiences unfold.

Developing an organization from afar would also look vastly different. The kinds of jobs would be different and would need reworked. How information flows through the organization could be enhanced with a discussion and communication protocol. Information dissemination would be a major concern, as most informal communication would either cease or be different.

All remote work and workflow should not happen by chance, but no article offered a formal plan from the beginning to the end of a workday. Besides five articles, all research was either theoretical or general in nature. Only Tsareva and Yu (2020) and Manokha (2020) included specific technological platforms for employee monitoring. Jensen et al. (2020) provided a direct field study of remote work and workflow, the only study of its kind located. There was 
mention of the need for a standardized approach, but no article provided a full picture.

\section{Discussion}

The one ubiquitous factor about all online learning, from preschool to college, is remote work and workflow define an educator's workday. The scoping review revealed little research into the structure of workflow for public educators, though there was a growing body of research into the effects of working from home. Educational leadership studies have not focused on an issue - workflow - which impacts every student and educational professional every minute of every day. Two questions remain unanswered: What do teachers do during the workday? How does one measure productivity? There might be fraud and mismanagement, but both factors were undefined.

Fayol's management theory points to the development of a unity of purpose (Godwin et al., 2017). Current research does not define how or what educational professionals do in the home work environment. Coker (2021) found teachers were overburdened, stressed, and bewildered, and the proposal was for a theory of holistic schooling. Within the holistic schooling paradigm, schools must more beyond remote learning and consider the academic, physical, emotional, and social aspect to develop a community. There might be a fifth element: spiritual. Within a workflow framework, Gómez et al. (2020) suggested flexibility, contingency planning, and training and support would improve the implementation of a systematic approach to remote work.

Future research into workflow needs to consider the development of a work-home environment and the maintenance of social connections. There were distractions and technological concerns, with childcare and supervision impacting how a worker stays at home but redefines the space as not as home (Baudot \& Kelly, 2020; Ozimek, 2020). Madan et al. (2020) stated all the problems of remote work need considered within the confines of work which require human proximity. Most of what passes for competent instructional practices were unscripted and based on observation of students' work and emotional responses. Teachers as a profession were often unsupervised within one's own classroom, whereas in a physical location, supervision and monitoring happened unplanned and sporadically. The disruption in workflow removed even a cursory leadership and management role.

Management must develop procedures to monitor productivity and motivation. Recognition and rewards will be administered differently within a remote working environment, as traditional methods might be no longer valid (Agarwal, 2020). Self-discipline has been studied as a problem within remote work (Wang et al., 2021), though the scoping review suggested self-discipline is a problem because of a lack of meaningful leadership and supervision. There was a plethora of studies suggesting digital platforms and barriers (e.g., Kaur \& Kaur, 2020), but no identified research produced a comprehensive plan how to work from home.

The lack of a deliberate design in remote work and work flow (Sethi \& Saini, 2020) has caused problems throughout schools and resulted in knowledge fragmentation (Ferreira et al., 2021). Loneliness, though mediated by control of time, remains a major problem beyond supervision (Buchanan et al., 2021). Autonomy has proven to be a major enhancement to remote workers, but the paradox has been autonomy has also caused an erosion of having a regularity to one's day and life (Ratz et al., 2021). Considering all the parameters of a holistic schooling 
experience could reimagine the possibilities of a new educational work experience which is largely unmonitored.

\section{Recommendations}

There are many recommendations to improve remote learning which would directly impact workflow, such as reconfiguring schools by need versus age and the development of curricular repositories, etc. (Coker, 2020b). There is a void in the composition of a systematic plan for remote work, so a patchwork of procedures developed. Looking beyond, three recommendations could alter the workflow landscape within the spatial and temporal realm. First, Fayol's principles could guide the development of casting workflow to a remote environment. Secondly, a formal policy of remote work and workflow could define and implement expectations around a holistic schooling experience. Third, leadership and management must become standard and present within a remote environment.

The nature and structure of work for teachers changed dramatically (Kaden, 2020). Leadership and management must revolve around a cohesive organizational presentation using a comprehensive digital platform which meets the holistic needs of the individual. The platform will monitor the digital exhaust in real time and produce a dashboard which would allow all parties to participate, be monitored, receive feedback, and maintain social and emotional connections. Every action of the professional educator, from tablets and laptops to apps on a cellphone could be recorded and utilized for enhancement and refinement of workflow to improve productivity. Physical and spiritual health would need explicitly considered.

Many of the tools needed exist and continue to be used by private industry. A dashboard should move beyond seeing someone logged in for attendance purposes; from chatting to making calls to downtime, there are ways to ensure work from home is work from home. An example could be a dashboard displaying a picture and the screen of all supervised employees, with a robust mechanism to communicate. Virtual and augmented reality, as well as artificial intelligence, could automate many of the processes and help to define the future direction of remote work and workflow. Technology should not be the driver, but the lack of use within remote work beyond as a tool for curriculum and instruction is a daunting challenge. Social and emotional connectivity, as well as physical wellbeing, mean workflow cannot have employees sit and work all day without exercise, social connections, and emotional support.

\section{Limitations}

There were some limitations. First, the scoping review was only conducted using two databases for a limited time period. Secondly, only one researcher reviewed and coded data. Still, the researcher has published and consulted on the structure of remote work and workflow within education, and both concepts were scarcely mentioned in the popular and academic literature. Remote learning and the problems of remote work were very popular and well researched, but the practicality of managing and leading remote work through the development of workflow remains largely on the fringe.

Future recommendations are twofold. A more expansive review of the structure of remote work and workflow would improve the results and recommendations. Universities, corporations, and public school entities should collaborate on the development, 
implementation, and research of remote work structures. Direct field studies will be needed. Adapting existing technological solutions into a coherent system should be a driver of the development of workflow.

\section{References}

Agarwal, V. (2020). Modernizing rewards and recognition (R\&R) practices in the digital world Psychology and Education Journal, 57(9), 3722-3729.

Aropah, V. D. W., \& Sumertajaya, I. M. (2020). Factors affecting employee performance during work from home. International Research Journal of Business Studies, 13(2), 201-214. https://doi.org/10.21632/irjbs.13.2.201-214

Bartnicka, J., Kabiesz, P., \& Kaźmierczak, J. (2020). Standardization of human activities as the component of a workflow efficiency model-a research experiment from a meat producing plant. Production Engineering Archives, 26(2). https://doi.org/10.30657/pea.2020.26.15

Bartosiak, N. (2020). Conditions for effective organization management during remote work. International Interdisciplinary Scientific Journal, 1, 1-20.

Baudot, L., \& Kelly, K. (2020). A survey of perceptions of remote work and work productivity in the United States during the COVID-19 shutdown. https://doi.org/10.2139/SSRN.3646406

Bond, M. (2020). Schools and emergency remote education during the COVID-19 pandemic: A living rapid systematic review. Asian Journal of Distance Education, 15(2), 191-247.

Buchanan, N. D., Aslaner, D. M., Adelstein, J., MacKenzie, D. M., Wold, L. E., \& Gorr, M. W. (2021). Remote work during the COVID-19 pandemic: Making the best of it. Physiology, 36(1), 2-4. https://doi.org/10.1152/physiol.00035.2020

Carrillo, C., \& Flores, M. A. (2020). COVID-19 and teacher education: A literature review of online teaching and learning practices. European Journal of Teacher Education, 43(4), 466-487. https://doi.org/10.1080/02619768.2020.1821184

Coker, D. C. (2020a). The canary in the mine: Remote learning in the time of COVID-19. Journal of Curriculum and Teaching, 9(3), 76-87. https://doi.org/10.5430/jct.v9n3p76

Coker, D. C. (2020b). Revolution in remote learning: A plan for radical improvement. A policy recommendation to transform technology to improve student learning. In EdMedia+ Innovate Learning (pp. 329-343). Association for the Advancement of Computing in Education (AACE).

Coker, D. C. (2021). Education, policy, and juvenile delinquents: A mixed methods Investigation during COVID-19. Journal of Education and Learning, 10(1), 22-38. https://doi.org/10.5539/jel.v10n1p22

Ferreira, R., Pereira, R., Bianchi, I. S., \& da Silva, M. M. (2021). Decision factors for remote work adoption: Advantages, disadvantages, driving forces and challenges. Journal of Open Innovation: Technology, Market, and Complexity, $7(1), \quad 70$. https://doi.org/10.3390/joitmc7010070

Godwin, A., Handsome, O., Ayomide, W., Enobong, A., \& Johnson, F. (2017). Application of the Henri Fayol principles of management in startup organizations. Journal of Business and Management, 19(10), 78-85.

Gómez, S. M., Mendoza, O. E. O., Ramírez, J., \& Olivas-Luján, M. R. (2020). Stress and 
myths related to the COVID-19 pandemic's effects on remote work. Management Research: Journal of the Iberoamerican Academy of Management. https://doi.org/10.1108/MRJIAM-062020-1065

Graves, L. M., \& Karabayeva, A. (2020). Managing virtual workers - strategies for success. IEEE Engineering Management Review, 48(2), 166-172. https://doi.org/10.1109/EMR. 2020.2990386

Harzing, A. W. (2007). Publish or Perish.

Hope, J. (2020). Working from home? Follow these tips for successful remote work. The Successful Registrar, 20(3), 9-9. https://doi.org/10.1002/tsr.30713

Howard-Grenville, J. (2020). How to sustain your organization's culture when everyone is remote. MIT Sloan Management Review, 61(4), 1-4.

Ilag, B. N. (2021). Tools and technology for effective remote work. International Journal of Computer Applications, 174(21), 13-16.

Jensen, N., Lyons, E., Chebelyon, E., Le Bras, R., \& Gomes, C. (2020). Conspicuous monitoring and remote work. Journal of Economic Behavior \& Organization, 176, 489-511. https://doi.org/10.1016/j.jebo.2020.05.010

Kaden, U. (2020). COVID-19 school closure-related changes to the professional life of a K-12 teacher. Education Sciences, 10(6), 165. https://doi.org/10.3390/educsci10060165

Karanikas, N., \& Cauchi, J. (2020). Literature review on parameters related to work-from-home (WFH) arrangements. Queensland University of Technology. Retrieved from https://eprints.qut.edu.au/

Kastner, M., Tricco, A. C., Soobiah, C., Lillie, E., Perrier, L., Horsley, T., ... \& Straus, S. E. (2012). What is the most appropriate knowledge synthesis method to conduct a review? Protocol for a scoping review. BMC Medical Research Methodology, 12(1), 1-10. https://doi.org/10.1186/1471-2288-12-114

Kaur, R., \& Kaur, G. (2020). A study on work from home in education industry due to COVID-19. International Journal of Social and Humanistic Computing, 3(3-4), 339-358. https://doi.org/10.1504/IJSHC.2020.111196

Knight, M., \& Taylor, R. (2020). Flexible work strategies for public accounting: Well-designed procedures can help CPA firms make effective use of remote work and employee-friendly scheduling. Journal of Accountancy, 229(2), 22.

Kuhfeld, M., Soland, J., Tarasawa, B., Johnson, A., Ruzek, E., \& Liu, J. (2020). Projecting the potential impact of COVID-19 school closures on academic achievement. Educational Researcher, 49(8), 549-565. https://doi.org/10.3102\%2F0013189X20965918

Kusumaningtiar, D. A., \& Anggraini, D. (2020). Factors related to work stress in elementary school teachers in East Cengkareng Village during work from home. In International Conference of Health Development. Covid-19 and the Role of Healthcare Workers in the Industrial Era (ICHD 2020) (pp. 86-91). https://doi.org/10.2991/ahsr.k.201125.016

Larson, B. Z., Vroman, S. R., \& Makarius, E. E. (2020). A guide to managing your (newly) remote workers. Harvard Business Review, 18.

Leonardi, P. M. (2020). COVID-19 and the new technologies of organizing: digital exhaust, 
digital footprints, and artificial intelligence in the wake of remote work. Journal of Management Studies. https://dx.doi.org/10.1111\%2Fjoms. 12648

Limoncelli, T. A. (2020). Five nonobvious remote work techniques: Emulating the efficiency of in-person conversations. Queue, 18(3), 29-38. https://doi.org/10.1145/3411757.3417752

Lopez-Leon, S., Forero, D. A., \& Ruiz-Díaz, P. (2020). Recommendations for working from home during the pandemic (and Beyond). Work, (Preprint), 1-5. https://doi.org/10.3233/ WOR-203187

Lord, P. (2020). The social perils and promise of remote work. Journal of Behavioral Economics for Policy, 62(4). https://doi.org/10.2139/ssrn.3613235

Madan, N., Mani, D., \& Pillutla, M. (2020). The impact of job need for human proximity and communication technologies on remote work efficacy. https://doi.org/10.2139/ssrn.3675478

Manokha, I. (2020). Covid-19: Teleworking, surveillance and 24/7 work. Some reflexions on the expected growth of remote work after the pandemic. Political Anthropological Research on International Social Sciences (PARISS), 1(2), 273-287 https://doi.org/10.1163/25903276 -BJA10009

Mardianah, L., \& Hidayat, S. (2020). Empirical study of the impact of work from home (WFH) policy and top management support on employee performance. Journal of Research in Business, Economics, and Education, 2(5), 1039-1045.

Mesquita, A., Oliveira, A., Oliveira, L., \& Sequeira, A. (2020). Are we ready for remote work? Preliminary results from Portugal. CAPSI 2020 Proceedings. 22.

O'Flaherty, J., \& Phillips, C. (2015). The use of flipped classrooms in higher education: A scoping review. The Internet and Higher Education, 25, 85-95. https://doi.org/10.1016/ j.iheduc.2015.02.002

Ozimek, A. (2020). The future of remote work. https://doi.org/10.2139/ssrn.3638597

Popovici, V., \& Popovici, A. L. (2020). Remote work revolution: Current opportunities and challenges for organizations. Ovidius University Annals, Economic Sciences Series, 20(1), 468-472.

Ratz, N., Reibenspiess, V., \& Eckhardt, A. (2021). The secret to remote work-results of a case study with dyadic interviews. In Proceedings of the 54th Hawaii International Conference on System Sciences (p. 712). https://doi.org/10.24251/HICSS.2021.087

Ravanelli, D. M., Putri, R. P. E., Putri, Z. K., \& Jannah, L. M. (2020, December). Teacher's readiness level in implementing work from home policy in Indonesia. In Iapa Proceedings Conference (pp. 637-661). https://doi.org/10.30589/proceedings.2020.431

Rusdiana, A., Huda, N., Mu'in, A., \& Kodir, A. (2020). The effectiveness of educational supervision in increasing the teacher's professional competence in the Covid-19 pandemic period. International Journal of Innovation, Creativity and Change, 14(5), 918-942.

Sethi, G. K., \& Saini, N. K. (2020). COVID-19: Opinions and challenges of school teachers on work from home. Asian Journal of Nursing Education and Research, 10(4), 532-536. https://doi.org/10.5958/2349-2996.2020.00115.9

Sliż, P. (2020). Remote work during the COVID-19 epidemic in Poland-results of an empirical study. E-mentor, 3(85). https://doi.org/10.15219/em85.1474 


\section{Macrothink}

International Research in Education

ISSN 2327-5499

2021, Vol. 9, No. 2

Smith, R. W., Kim, Y. J., \& Carter, N. T. (2020). Does it matter where you're helpful? Organizational citizenship behavior from work and home. Journal of Occupational Health Psychology, 25(6), 450-468. https://doi.org/10.1037/ocp0000181

Sull, D., Sull, C., \& Bersin, J. (2020). Five ways leaders can support remote work. MIT Sloan Management Review, 61(4), 1-10.

Tanpipat, W., Lim, H. W., \& Deng, X. (2021). Implementing remote working policy in corporate offices in Thailand: Strategic facility management perspective. Sustainability, 13(3), 1284. https://doi.org/10.3390/su13031284

Tricco, A. C., Lillie, E., Zarin, W., O’Brien, K., Colquhoun, H., Kastner, M., ... \& Straus, S. E. (2016). A scoping review on the conduct and reporting of scoping reviews. BMC Medical Research Methodology, 16(1), 1-10. https://doi.org/10.1186/s12874-016-0116-4

Tricco, A. C., Lillie, E., Zarin, W., O'Brien, K. K., Colquhoun, H., Levac, D., ... \& Straus, S. E. (2018). PRISMA extension for scoping reviews (PRISMA-ScR): checklist and explanation. Annals of Internal Medicine, 169(7), 467-473. https://doi.org/10.7326/M18-0850

Tsareva, N. A., \& Yu, S. (2020). Remote work: Development of employee digital competence. Revista de la Universidad del Zulia, 11(31), 131-140. https://doi.org/10.46925//rdluz.31.10

van Eck, N. J., \& Waltman L. (2010). Software survey: VOSviewer, a computer program for bibliometric mapping. Scientometrics, 84(2), 523-538. https://doi.org/10.1007/s11192009-0146-3

Wang, B., Liu, Y., Qian, J., \& Parker, S. K. (2021). Achieving effective remote working during the COVID-19 pandemic: A work design perspective. Applied Psychology, 70(1), 16-59. https://doi.org/10.1111/apps. 12290

Whillans, A., Perlow, L., \& Turek, A. (2021). Experimenting during the shift to virtual team work: Learnings from how teams adapted their activities during the COVID-19 pandemic. Information and Organization, 100343. https://doi.org/10.1016/j.infoandorg.2021.100343

Wren, D. A., Bedeian, A. G., \& Breeze, J. D. (2002). The foundations of Henri Fayol's administrative theory. Management Decision, 39(6), 475-487. https://doi.org/10.1108/ EUM0000000005565

\section{Copyright Disclaimer}

Copyright reserved by the authors.

This article is an open-access article distributed under the terms and conditions of the Creative Commons Attribution license (http://creativecommons.org/licenses/by/4.0/). 